\title{
Surface Properties and Biological Activity of the Synthesized Polymeric Surfactant and its Complexes
}

\author{
Ahmed Adawy 1 (D), Salwa El-Mesallamy ${ }^{2}$ (D), Emad Badr ${ }^{\text {(iD }}$, Zizi Abdeen 2,* (D) \\ 1 Surfactants lab., Petrochemicals department, Egyptian Petroleum Research Institute (EPRI), Egypt; \\ chem_ahmedadawy@yahoo.ca (A.A.), emadbadr@yahoo.com (E.B.); \\ 2 Polymers lab., Petrochemicals department, Egyptian Petroleum Research Institute (EPRI), Egypt; s_162_m@yahoo.com; \\ (S.E.M.), ziziabdeen@yahoo.com (Z.A.); \\ * Correspondence: ziziabdeen@yahoo.com (Z.A.);
}

Scopus Author ID 35298711400

Received: 30.04.2021; Revised: 5.07.2021; Accepted: 8.07.2021; Published: 7.09.2021

\begin{abstract}
Poly (4-vinyl pyridine) (P4-VP) was quaternized and complexed with salt chloride to obtain polymeric surfactant complexes having to improve surface properties and microbial activity. P4-VP was quarternized by trimethyl chloro silane to give (QP4-VP) (I) and then complexed by using stannous chloride and cobalt chloride to give polymeric surfactant complexes. The quaternized P4-VP and its complexes were characterized by Fourier transform infrared spectroscopy (FTIR) and scanning electron microscopy (SEM). Also, the surface properties of this polymeric surfactant and its complexes were studied. The influence of metal chlorides on the antibacterial activity of this polymeric surfactant was estimated and screened through the length of the field of hindrance versus various microorganisms. It shows an enhancement in the surface characteristics and fine germicidal action for quaternized P4-VP when complexed with metal chlorides. The designed cationic polymeric surfactant and its complexes have a good biological action against all such microorganisms.
\end{abstract}

Keywords: poly (4-vinyl pyridine); quaternization; biological activities; polymeric surfactants; complexes.

(C) 2021 by the authors. This article is an open-access article distributed under the terms and conditions of the Creative Commons Attribution (CC BY) license (https://creativecommons.org/licenses/by/4.0/).

\section{Introduction}

The inherent antimicrobial properties of poly(vinylpyridine) (PVP) may be adjusted using post operations at the tertiary nitrogen group of reactive pendant pyridine moieties to form quaternized poly(vinylpyridine) (PVP), which has efficient antimicrobial properties versus the cells of various microorganisms [1]. To form the strong polyelectrolytes in solution, the polymers are quaternized with derivatives of alkyl. A choice to obtain the polymers with quaternary ammonium, perhaps the polyvinyl pyridines quaternization. The vinyl pyridinium monomers preparation is nearly impossible because of their spontaneous polymerization yielding in the main chain, the pyridinium moieties [2]. Additionally, the P (4-VP) post quaternization is not carry on among numerical transformations. $65-70 \%$ of quaternization using alkyl halides is mostly attributed to the neighboring group's effect [3]. The quantitative quaternization of $\mathrm{P}$ (4-VP) was studied using trimethyl chloro silane and then complexed using ferric chloride [4].

Qaternization by various alkylating agents expands the range of products applies. The cation of polypyridinium, having a changeable composition of the alkylating/quaternizing operator, has many properties such as emulsifying, antimicrobial, catalytic, and water- 
softening [5,6]. The ions of polypyridinium benefit from active group high local concentration and are so further efficient than the less molecular weight analogs. The actions of pyridinium polymers as antimicrobial are considered to be influenced through different features of polymer composition, such as molecular weight, counter anions kind, and alkyl chain length [7]. It was found that the antibacterial activity can be affected by the counter anion structure of less activity for a counter anion, be likely forming a big compacted ion-pair that promotes ionic separation to liberated ions [8]. The biocidal achievement of cationic surfactants seems to stand towards their capability to disorder and dislocate the vital microbial film by combining the hydrophobic and electrostatic adsorption processes on the film-water interface $[9,10]$. The cell film of the pathogenic bacteria has negative charges opposite to the eukaryotic cells $[10,11]$. Therefore, the oppositely charged cationic amphiphile makes easy their interaction with the membrane of bacteria. The aim of this work, the P (4-VP) is quaternized with trimethyl chloro silane, and then complexes among two various metals chloride producing polymeric surfactant complexes (Ia) and (Ib), respectively. As well, the quaternized P4-VP and its complexes were characterized besides discussing their surface characteristics. Furthermore, the metal chloride's impact on the antibacterial activity of this polymeric surfactant was assessed and calculated through the length of the field of hindrance in opposition to various microbes.

\section{Materials and Methods}

\subsection{Materials.}

Poly-4-vinyl pyridine $(60,000)$, trimethyl chloro silane, and dimethylformamide were (AR) and purchased from Sigma Aldrich Company. But, hydrated stannous chloride and hydrated cobalt chloride were (AR) and purchased from LOBA Chemie Company. In addition, the entire chemicals considered being (AR) and were bought from Adwic group.

\subsection{Production of (N-trimethylsilane poly-4-vinyl pyridinium chloride) $Q(I)$}

Poly-4- vinyl pyridine (60.000) (5.25 g, 0.05-mole repeating unit) was soluble in $25 \mathrm{ml}$ DMF and 75.0 mmole tri methyl chloro silane. The mixture was moved at an ordinary temperature. The solution changed to a pale yellow, and a white residue formed at once from quaternary salt (N-trimethylsilane poly-4-vinyl pyridinium chloride) Q (I). In the final of the experiment, the solution was filtered and bathed with acetone $(50 \mathrm{ml})$ and ether $(25 \mathrm{ml})$. Vacuum dehydrated yields were put in compactly closed dark containers [4]. The quaternization reaction is revealed through the following scheme 1.

\subsection{Production of metallo polymeric surfactants $(I a, I b)$.}

Production of metallo polymeric surfactant complexes was through the reflux process of N-trimethylsilane poly-4-vinyl pyridinium chloride Q (I) dissolved in methanol once with a mole of stannous chloride ( $\mathrm{SnCl}_{2} \cdot 2 \mathrm{H}_{2} \mathrm{O}$ ) for four hours to give polymeric surfactant complex (Ia) and another time with a mole of cobalt chloride $\left(\mathrm{CoCl}_{2} \cdot 6 \mathrm{H}_{2} \mathrm{O}\right)$ also dissolved in methanol for four hours to give polymeric surfactant complex (Ib) [10]. In the final of the experiment, the solution was filtered and bathed with methanol, scheme 1. 


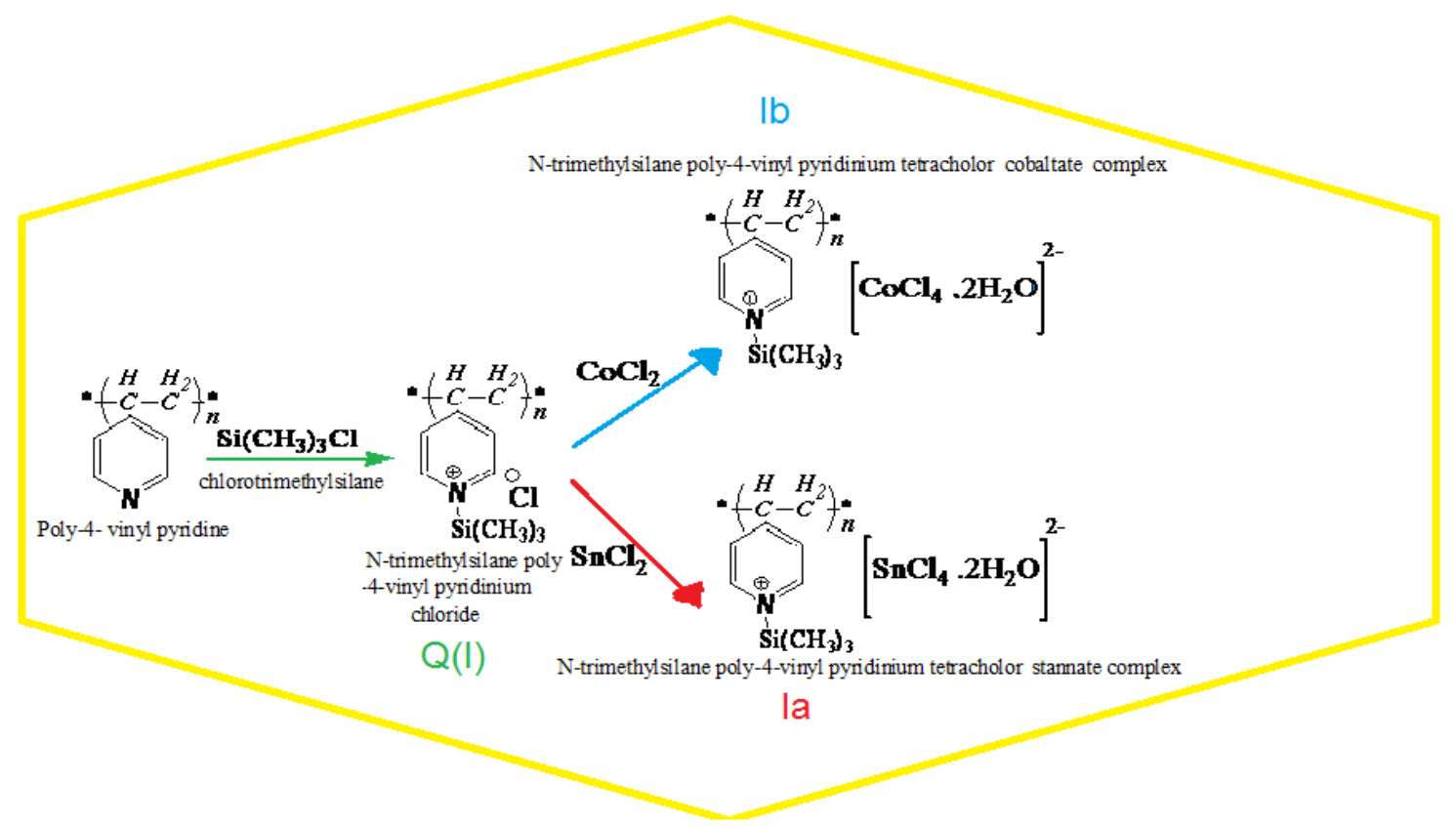

Scheme 1. Preparation of N-trimethylsilane poly-4-vinyl pyridinium complexes (Ia, Ib).

\subsection{Spectral measurements.}

The composition of the designed compounds was achieved through utilizing the IR transmission spectroscopic. The examination was passed in ordinary temperature on FT-IR, JASCO, Nicolet IS-10 (made in Japan) spectrometer utilizing $\mathrm{KBr}$ disc process through a spectral resolution of $4 \mathrm{~cm}^{-1}$ over the wavenumber scope of $400-4000 \mathrm{~cm}^{-1}$. And, the surface morphology of the specimen was checked from micrographs picked with scanning electron microscopy (SEM, TOPCON ABT150S, and Japan). Before the monitoring, specimens were put above metal grids then layered using gold over the vacuum.

\subsection{Assessment technique of surface-active characteristics.}

\subsubsection{Surface tension.}

The surface tension of the solutions of designed cationic polymeric surfactant Q (I) and its complexes Ia and Ib were assigned utilizing Du-Nouy Tensiometer (Kruss type 6). The surface tension of various concentrations scope of 0.04 to $1.9 \times 10^{-5}$ mole/liter at several temperatures $\left(35,45,55\right.$, and $\left.65^{\circ} \mathrm{C}\right)$ was estimated.

\subsubsection{Surface characteristics of the designed structures.}

\subsubsection{Critical micelle concentration (CMC).}

The surface tension process was utilized to assign the points of the critical micelle concentration for the designed structures. Scores of the surface tension statistics were plotted versus the respective concentrations. The points of the surface tension measurements consider being plotted versus the equivalent concentrations. The CMC points were stated as the interrupt alter in the SC curves. 


\subsubsection{Effectiveness $\left(\pi_{C M C}\right)$.}

The variance between the surface tension of the pure water $\left(\gamma_{0}\right)$ and the surface tension of the surfactant solution $(\gamma)$ at the critical micelle concentration represents the effectiveness $\pi_{\mathrm{CMC}}$.

$$
\pi_{\mathrm{CMC}}=\gamma_{\mathrm{o}}-\gamma_{\mathrm{CMC}}
$$

\subsubsection{Efficiency $\left(P c_{20}\right)$.}

The concentration of the surfactant solution proficient at putting down the surface tension by $20 \mathrm{mN} / \mathrm{m}$ is defined as the Efficiency $\left(\mathrm{Pc}_{20}\right)$.

\subsubsection{Maximum surface excess $\Gamma_{\max }$}

The points of the maximum surface excess $\Gamma_{\max }$ are estimated from the surface or interfacial information through applying the Gibbs equation [12].

$\Gamma_{\max }=-1 / 2.303 \mathrm{nRT}(\delta \gamma / \delta \log \mathrm{C})_{\mathrm{T}}$

Where

$\Gamma_{\max } \quad$ maximum surface excess in mole $/ \mathrm{cm}^{2}$

$\mathrm{n} \quad$ The digit of solute classes whose concentration at the interface changes with the vary in the value of $C$.

$\mathrm{R} \quad$ universal gas constant $8.31 \times 10^{7} \mathrm{ergs} \mathrm{mole}^{-1} \mathrm{~K}^{-1}$

$\mathrm{T} \quad$ absolute temperature $\left(273.2+{ }^{\circ} \mathrm{C}\right)$

$\delta \gamma \quad$ surface pressure in dyne/cm

C surfactant concentration

$(\delta \gamma / \delta \log C)_{\mathrm{T}} \quad$ is the slope of a plot surface tension vs. $-\log$ concentration curves under CMC at a fixed temperature.

\subsubsection{Minimum surface area $\left(A_{\min }\right)$.}

The details of the level of filling and the trend of the adsorbed molecules are demonstrated from the area per molecule at the interface $\left(\mathrm{A}_{\min }\right)$.

The mean region (in square angstrom) engaged by an individual particle adsorbed on the interface [13] is specified by:

$$
\mathrm{A}_{\min }=10^{16} / \Gamma_{\max } \mathrm{N}
$$

$\Gamma_{\max }$ maximum surface excess in mole $/ \mathrm{cm}^{2}$

$\mathrm{N} \quad$ Avogadro's number $6.023 \times 10^{23}$

\subsubsection{Thermodynamic characteristics of micellization and adsorption.}

The thermodynamic characteristics of adsorption and micellization of the designed polymeric surfactant I and its complexes Ia and Ib consider being computed through Gibb's adsorption equations number (4) according to Rosen [14]:

$\Delta \mathrm{G}_{\text {mic }}^{\mathrm{O}}=\mathrm{RT} \ln (\mathrm{CMC})$

$\Delta \mathrm{G}_{\text {ads }}^{\mathrm{O}}=\Delta \mathrm{G}_{\text {mic }}^{\mathrm{O}}-6.023 \times 10^{-1} \mathrm{X} \pi_{\mathrm{CMC}} \mathrm{X} \mathrm{A}_{\text {min }}$

$\Delta \mathrm{S}_{\text {mic }}=-\mathrm{d}\left(\Delta \mathrm{G}^{\mathrm{O}}{ }_{\text {mic }} / \Delta \mathrm{T}\right)$

$\Delta \mathrm{S}_{\mathrm{ads}}=-\mathrm{d}\left(\Delta \mathrm{G}_{\text {ads }}^{\mathrm{O}} / \Delta \mathrm{T}\right)$

$\Delta \mathrm{H}_{\text {mic }}=\Delta \mathrm{G}_{\text {mic }}^{\mathrm{O}}+\mathrm{T} \Delta \mathrm{S}_{\text {mic }}$ 
$\Delta \mathrm{H}_{\mathrm{ads}}=\Delta \mathrm{G}_{\mathrm{ads}}^{\mathrm{O}}+\mathrm{T} \Delta \mathrm{S}_{\mathrm{ads}}$

\subsection{Germicidal action of the designed structures.}

The germicidal action of the designed cationic polymeric surfactant I and its complexes $\mathrm{Ia}$ and $\mathrm{Ib}$ were screened separately versus diversity of microorganisms formerly separated in Biotechnology Lab. in Egyptian Petroleum Research Institute (EPRI) through various oilpolluted mediums utilizing quantity identical to $5 \mathrm{mg} / \mathrm{ml}$ by the diffusion agar procedure. The examined designed structures were estimated versus Gram -ve bacteria (Escherichia coli and Pseud. aeruginosa), Gram +ve bacteria (Bacillus subtilis and Staph. aureus), and Yeast (Candida albicans) and Filamentous Fungus (Aspergillus niger).

The bacteria and yeast were expanded on nutrient agar, whereas the fungus was expanded on Czapek`s Dox agar environment. The negative control was DMF which has not to have any biocidal action towards the examined microorganisms, while the positive control was Erythromycin for bacteria and Metronidazole for yeast and fungus. The entire inspections were established twice; furthermore, the recorded statistics are considered to be the mean of the gained outcomes.

\section{Results and Discussion}

\subsection{Characterizations of the designed materials.}

As shown in Figures 1 (a, b, and c), the IR spectra exposing several absorption bands just like proceed: the absorption band at $3055 \mathrm{~cm}^{-1}$ is related to $\mathrm{C}-\mathrm{H}$ stretching in aromatic, while the absorption band at $2803 \mathrm{~cm}^{-1}$ is relating to $\mathrm{C}-\mathrm{H}$ stretching in aliphatic. The absorption band around $2049 \mathrm{~cm}^{-1}$ is according to overtone, whereas the absorption bands at 1638 and $1609 \mathrm{~cm}^{-1}$ are related to $\mathrm{CH}=\mathrm{N}$ imine group, $2807-2784 \mathrm{~cm}^{-1}$ for the $\mathrm{CH}_{2}$ group, and 3055$3072 \mathrm{~cm}^{-1}$ for $\mathrm{N}^{+}$group for synthesized complexes, respectively. It changed to the upperfrequency band of $\mathrm{C}=\mathrm{C}$ due to quaternization, the $\mathrm{CH}_{2}$ bending band around $1457 \mathrm{~cm}^{-1}$, and the bands at $1256 \mathrm{~cm}^{-1} \& 1206 \mathrm{~cm}^{-1}$ are related to $\mathrm{Si}-\mathrm{C} \& \mathrm{C}-\mathrm{N}$ in that order.

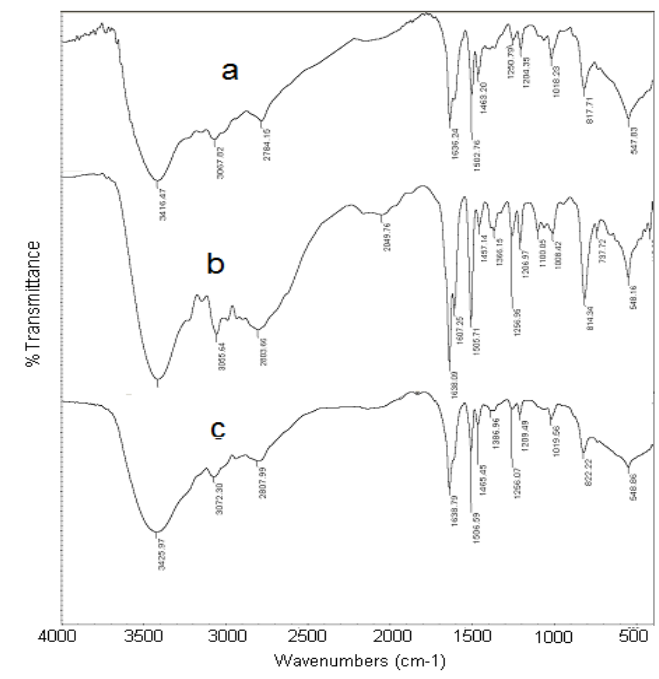

Figure 1. FTIR for Quaternary Q( I) (a), Complex Ia (b)and Complex Ib(c).

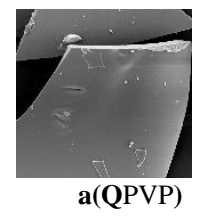

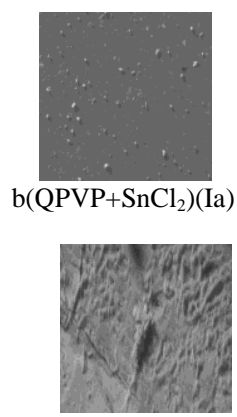

$\mathrm{d}\left(\mathrm{SnCl}_{2}\right)$
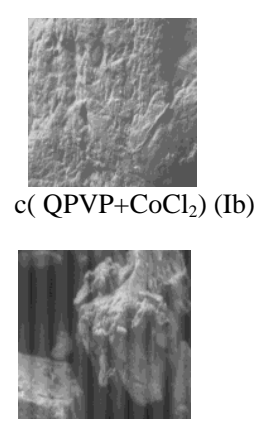

$\mathrm{e}\left(\mathrm{CoCl}_{2}\right)$
Figure 2. SEM images of quaternary Q (I) (a), complex C1 (Ia) (b), complex C2 (Ib) (c), $\mathrm{SnCl}_{2}(\mathrm{~d})$ and $\mathrm{CoCl}_{2}(\mathrm{e})$. 
At the same time, the absorption band at $820-746 \mathrm{~cm}^{-1}$ belongs to the bending of the aromatic ring. Figure 2 shows that the morphology of salts of chloride and QPVP before and after complexation. The morphology of QPVP appeared to have a smooth surface, Figure 2(a), and became rough after complexation with $\mathrm{SnCl}_{2}$, Figure 2 (b), confirming the complexation process. It appears that the SEM image of $\mathrm{SnCl}_{2}$ is rougher with pores, Figure 2(d) and became less when complexed with QPVP, Figure 2(b). But, concerning the morphology of $\mathrm{CoCl}_{2}$, Figure 2(e), the SEM image appears as bulky coagulation of particles compactly packed with each other and became less coagulation with pores when complexed with QPVP, as shown in Figure 2(c).

\subsection{Tensiometric parameters.}

The aqueous solutions of the designed polymeric surfactant and its complexes were set to estimate their surface tension at diverse temperatures $35,45,55,65^{\circ} \mathrm{C}$ using a surface tension system. The outcomes are also portrayed in Fig. 3. Surface tension diminishes with expanding concentration of the surfactants because of expanding the relocation of the designed structures in the mass pointing the solution surface and the surface tension of the metal-cationic polymeric surfactants $\mathrm{Ia}$ and $\mathrm{Ib}$ is more lowering than the surface tension of individual polymeric surfactant I as a result of maximizing the hydrophobicity [15]. Moreover, the figures demonstrated that the surface tension points minimize when the temperature maximizes to reach $65^{\circ} \mathrm{C}$ which persistently follows by reducing the dissolvability of the surfactants that orient to the surface [16]. The CMC scores of the synthesized polymeric structures were assigned through the curve of previous and next of micelle formation patterns at the interference break values of the two straight lines matched to the duration of the concentration defined via a gradual diminish in surface tension $(\gamma)$ and to the concentration area of almost stable surface tension, Table 1 . The setting of the $\mathrm{CMC}$ is known to be a significant parameter in light of the view of the reality that during that concentration, a large portion of the physical and chemical attributes of the surfactant solutions show a sudden variety. In like manner, growing the temperature reduces the $\mathrm{CMC}$ because the climb of temperature doubtlessly causes a reduction in the hydration of the hydrophilic moieties that prefer the formation of micelles. Of course, the rising of heat brings about the trouble of the sorted out water incorporating the hydrophobic moieties, an influence which dissatisfactions micellization. The general enormity of such two different impacts chooses if the CMC addition otherwise reduces across a given temperature broaden. The details in table 1 reveal that micellization is overhauled implies that CMC minimizes in the wake of raising the temperature $[17,18]$. The surface tension at the $\mathrm{CMC}$ of the designed polymeric structures solution decides the effectiveness. The surfactant which produces the best depress in surface tension for a critical micelle concentration (CMC) is considered the best surfactant. The scores of the effectiveness $\left(\pi_{\mathrm{CMC}}\right)$ pointed out that the compound ( $\mathrm{Ib}$ ) achieved the sharpest reduction of surface tension at (CMC) at $65{ }^{\circ} \mathrm{C}$, it is the best one, however, the efficiency $\left(\mathrm{P}_{\mathrm{C} 20}\right)$, i.e., the grouping of surfactant necessary delivering a $20 \mathrm{mNm}^{-1}$ decrease in surface tension, is diminished. From that worth, the surfactant focus is near the minimum concentration expected to deliver the most extreme adsorption at the interface. A further significant parameter that decides the surface action of the surfactant particles at the interface is the maximum surface excess, $\Gamma_{\max }$, this could be assessed by obeying the Gibbs adsorption isotherm: The scores of maximum surface excess in the surface considered being maximized in polymeric surfactant complexes Ia and Ib than the individual one I; as a result, $\Gamma_{\max }$ expanded demonstrating more saturation at the surface that means 
expanding surfactant particles quantity at the surface. Minimum surface area $\left(\mathrm{A}_{\min }\right)$ scores involved through the designed polymeric cationic surfactants at the interface, $A_{\min },\left(\mathrm{nm}^{2}\right)$ when the surface adsorption was full, basic data about the direct method of the particles at the interface could be given through the assign of the minimum surface area $\left(\mathrm{A}_{\min }\right)$. Expanding the amount of particles on the solution surface prompting an increment of the maximum surface excess scores; likewise, the region accessible for every particle will diminish. Accordingly, at the interface, there will be framed a dense condensing sheet of surfactant particles. The scores of minimum surface area are maximized in the individual polymeric surfactant $I$ than its complexes Ia and $\mathrm{Ib}$. The scores of CMC, $\pi_{\mathrm{CMC}}, \mathrm{P}_{\mathrm{C} 20}, \Gamma_{\max }$, and $\mathrm{A}_{\min }$ were displayed in Table 1. In a few words, it is evidently revealed that cationic polymeric surfactant complexes Ia and $\mathrm{Ib}$ perform the specified scores of the surface tension at a minor concentration as matched to the individual polymeric surfactant I. Accordingly, it can be accomplished that compounds Ia and $\mathrm{Ib}$ are extra tension-active than compound I and enlightening to large extent surface properties.

Table 1. Surface properties of polymeric surfactants at $35,45,55,65^{\circ} \mathrm{C}$.

\begin{tabular}{|c|c|c|c|c|c|}
\hline Surfactant & $\begin{array}{c}\text { CMC X 10-3, } \\
\text { Mole/liter }\end{array}$ & $\begin{array}{l}\pi_{\mathrm{CMC}}, \\
\mathrm{mN} / \mathbf{m}\end{array}$ & $\begin{array}{c}\mathrm{Pc}_{20} \mathrm{X} 1^{-3} \text {, } \\
\text { Mole/liter }\end{array}$ & $\begin{array}{c}\Gamma_{\max } X 10^{-11}, \\
\text { Mole/cm }\end{array}$ & $\begin{array}{c}\mathbf{A}_{\text {min }}, \\
\mathbf{n m}^{2}\end{array}$ \\
\hline I & 5.9 & 17.2 & - & 5.23 & 3.17 \\
\hline Ia $35^{\circ} \mathrm{C}$ & 4.6 & 18 & - & 5.25 & 3.16 \\
\hline Ib & 3.6 & 20 & 5 & 5.3 & 3.16 \\
\hline I & 4.4 & 17.7 & - & 4.6 & 3.6 \\
\hline Ia $45^{\circ} \mathrm{C}$ & 4 & 18.6 & 10 & 4.8 & 3.4 \\
\hline Ib & 3.2 & 20 & 2.5 & 4.9 & 3.4 \\
\hline I & 3.2 & 17.8 & 10 & 4.5 & 3.7 \\
\hline Ia $55^{\circ} \mathrm{C}$ & 3.1 & 20.2 & 2.5 & 4.9 & 3.4 \\
\hline Ib & 2.6 & 21 & 1.8 & 4.9 & 3.4 \\
\hline I & 2.7 & 18.2 & 7 & 4.1 & 4 \\
\hline Ia $65^{\circ} \mathrm{C}$ & 2.6 & 21.2 & 2 & 4.3 & 3.8 \\
\hline Ib & 2 & 21.5 & 1.6 & 5.2 & 3.2 \\
\hline
\end{tabular}

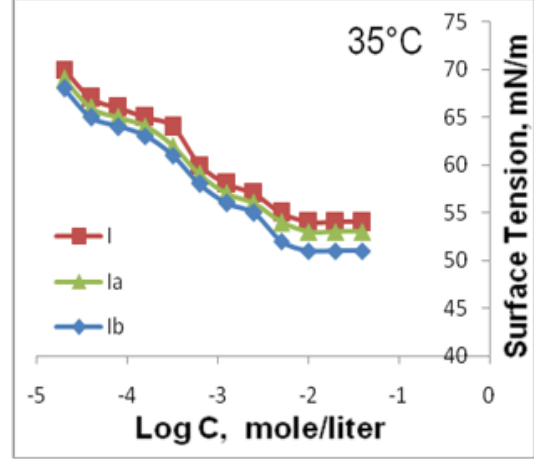

(a)

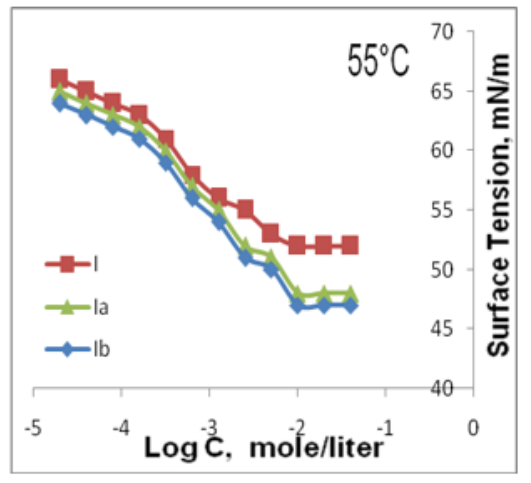

(c)

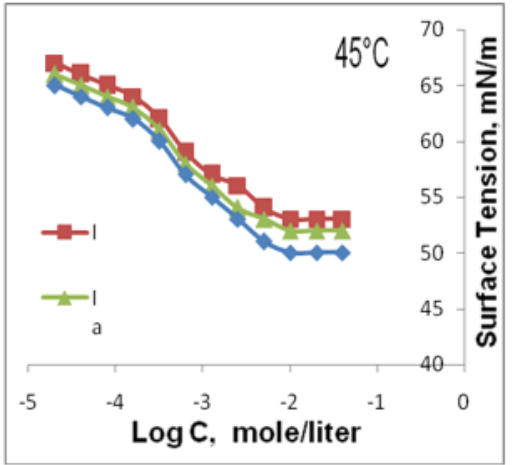

(b)

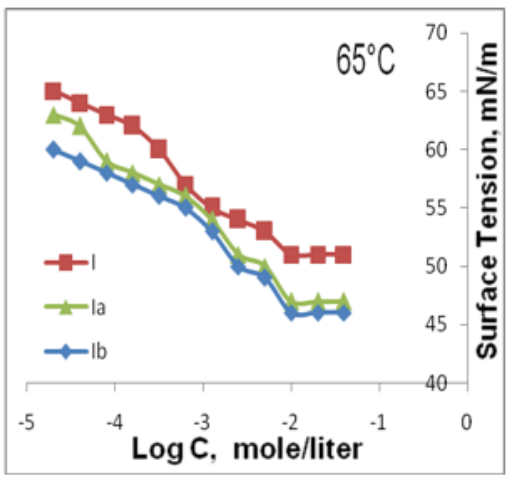

(d)

Figure 3. Surface tension vs. $\log$ Concentration of synthesized polymeric surfactants at: (a) $35^{\circ} \mathrm{C}$, (b) $45^{\circ} \mathrm{C}$, (c) $55^{\circ} \mathrm{C},(\mathrm{d}) 65^{\circ} \mathrm{C}$. 


\subsection{Thermodynamic of micellization and adsorption.}

The standard free energies of adsorption and micellization $\left(\Delta \mathrm{G}_{\text {ads }}^{\mathrm{o}}\right.$ and $\Delta \mathrm{G}^{\mathrm{o}}$ mic $)$ at several temperatures $35,45,55$, and $65^{\circ} \mathrm{C}$ were utilized for learning the thermodynamic manner of designed polymeric cationic surfactants and its complexes in their solutions. The values of the thermodynamic characteristics of micellization and adsorption were recorded in (Tables 2, 3). Clearly, the tables show that the scores of the standard free energies of adsorption and micellization of the designed polymeric surfactants and their complexes are considered to be constantly negative. This circumstance demonstrates that both adsorption and micellization forms happened automatically. Moreover, the standard free energies of adsorption of the three compounds at the air/water molecules have extra depressing values compared with the standard free energies of micellization, showing that the adsorption procedure is better than micellization $[19,20]$. Also, the huge contrast between $\Delta \mathrm{G}^{\mathrm{o}}$ ads and $\Delta \mathrm{G}^{\mathrm{o}}$ mic scores is ascribed to the way in which the adsorbed particles at the interface are subsequently profoundly compressed; the particles of the water don't associate essentially with these particles [20-23].

Table 2. Thermodynamic parameters of micellization of polymeric surfactants at $35,45,55,65^{\circ} \mathrm{C}$.

\begin{tabular}{l|c|c} 
Surfactant & $\boldsymbol{\Delta G}_{\mathbf{m i c}}^{\mathbf{O}}, \mathbf{K J} / \mathbf{m o l e}$ & $\boldsymbol{\Delta H}_{\mathbf{m i c}}, \mathbf{K J} \mathbf{J} \mathbf{m o l e}$ \\
\hline $\mathbf{I}$ & -13.1 & -50 \\
\hline $\mathbf{I a ~ 3 5}{ }^{\circ} \mathbf{C}$ & -13.8 & -38.4 \\
$\mathbf{I b}$ & -14.4 & -39 \\
\hline $\mathbf{I}$ & -14.3 & -52.2 \\
\hline $\mathbf{I a} \mathbf{4 5}{ }^{\circ} \mathbf{C}$ & -14.6 & -40 \\
$\mathbf{I b}$ & -15.2 & -40.6 \\
\hline $\mathbf{I}$ & -15.6 & -48.5 \\
\hline $\mathbf{I a ~ 5 5}{ }^{\circ} \mathbf{C}$ & -15.7 & -45.3 \\
$\mathbf{I b}$ & -16.2 & -55.6 \\
\hline $\mathbf{I}$ & -16.7 & -50.5 \\
\hline $\mathbf{I a ~} \mathbf{6 5}{ }^{\circ} \mathbf{C}$ & -16.6 & -47 \\
Ib & -17.4 & -58
\end{tabular}

Table 3. Thermodynamic parameters of adsorption of polymeric surfactants at $35,45,55,65^{\circ} \mathrm{C}$.

\begin{tabular}{|c|c|c|}
\hline Surfactant & $\Delta G_{\text {ads, }} \mathbf{K}^{\mathrm{K}} / \mathrm{mole}$ & $\Delta \mathbf{H}_{\text {ads }}, \mathrm{KJ} / \mathrm{mole}$ \\
\hline I & -46 & -249.4 \\
\hline Ia $35^{\circ} \mathrm{C}$ & -48 & -199 \\
\hline Ib & -52.5 & -172.7 \\
\hline I & -52.6 & -262.6 \\
\hline Ia $45^{\circ} \mathrm{C}$ & -52.9 & -208.8 \\
\hline Ib & -56.3 & -180.4 \\
\hline I & -55.3 & -160.3 \\
\hline Ia $55^{\circ} \mathrm{C}$ & -56.7 & -427.5 \\
\hline Ib & -58.8 & -165.3 \\
\hline I & -58.5 & -166.7 \\
\hline Ia $65^{\circ} \mathrm{C}$ & -68.2 & -450.3 \\
\hline Ib & -59 & -165.8 \\
\hline
\end{tabular}

\subsection{Antimicrobial activity of the designed compounds.}

The lipids and protein are the main constituents in the cell film of the microorganism; they present in few sheets ordered with each other in a particular order named bilayer or multilayer lipoprotein membrane [24, 25], and the hydrophobic character of the cell film is attributed to the existence of the lipids as the main component of its structure [26]. The activity method of that cationic polymeric surfactant $\mathrm{I}$ and its complexes $\mathrm{Ia}$ and $\mathrm{Ib}$ on the microorganism are clarified because of an electrostatic contact and physical disturbance [27, 28]. The positive charges that exist on the head moieties of the antimicrobial particles attract the reverse charge sites present in the film of the cell through the electrostatic contact process 
[29]. The physical disturbance is attributed to the entrance of the hydrophobic moiety inside the cell film because of the likeness of the concoction nature that prompts its passing [30]. The decreasing in the osmotic stability of the cell membranes results from biocides adsorption power onto these membranes, leading to disruption of intracellular constituents, which bothers the metabolic route inside the cytoplasm, driving to dying table 4. The results are shown in Table 4 that the synthesized polymeric surfactant [31-33] and its complexes have a good activity towards different microorganisms [34-38].

Table 4. The biological activity results of the synthesized polymeric surfactant and its complexes $5 \mathrm{mg} / \mathrm{ml}$

\begin{tabular}{|c|c|c|c|c|c|c|}
\hline $\begin{array}{c}\text { Test } \\
\text { organisms } \\
\text { Compuond ID }\end{array}$ & $\begin{array}{c}\text { Bacillus } \\
\text { subtilis }\end{array}$ & $\begin{array}{l}\text { Staph. } \\
\text { aureus }\end{array}$ & $\begin{array}{l}\text { Escherichi } \\
\quad \text { a coli }\end{array}$ & $\begin{array}{c}\text { Pseud. } \\
\text { aeruginosa }\end{array}$ & $\begin{array}{l}\text { Candida } \\
\text { albicans }\end{array}$ & $\begin{array}{c}\text { Aspergillus } \\
\text { niger }\end{array}$ \\
\hline I (Quaternary) & 10 & 11 & 7 & 9 & 12 & 8 \\
\hline Ia (Complex1) & 12 & 12 & 13 & 15 & 14 & 12 \\
\hline Ib (Complex2) & 17 & 19 & 15 & 16 & 17 & 18 \\
\hline Reference & 31 & 30 & 29 & 29 & 26 & 27 \\
\hline
\end{tabular}

\section{Conclusions}

Based on the trial outcomes, the accompanying conclusions can be reasoned from the current work:

The surface tension computations showed the good surface activity of the designed cationic polymeric surfactant I and its complexes Ia and Ib.

The efficiency $\left(\mathrm{Pc}_{20}\right)$ and effectiveness $\left(\Pi_{\mathrm{CMC}}\right)$ of the designed compounds showed their good surface action, while the maximum surface excess $\left(\Gamma_{\max }\right)$ showed the power of all such compounds to gather at the interface.

The germicidal action of all such engineered polymeric structures was estimated and screened through the length of the field of hindrance against various microorganisms. It was found from the results that all such compounds showed biocidal activity towards various microorganisms. The designed cationic polymeric surfactant I and its complexes Ia and Ib have good biological action against all such microorganisms.

\section{Funding}

This research received no external funding.

\section{Acknowledgments}

The authors are significantly grateful to the Egyptian Petroleum Research Institute (EPRI) for money-related help.

\section{Conflicts of Interest}

The authors declare no conflict of interest. 


\section{References}

1. Allison, B.C.; Applegate, B.M.; Youngblood, J.P. Hemocompatibility of Hydrophilic Antimicrobial Copolymers of Alkylated 4-Vinylpyridine. Biomacromolecules 2007, 8, 2995-2999, https:///doi.org/10.1021/bm7004627.

2. Chovino, C.; Gramain, P. Influence of the Conformation on Chemical Modification of Polymers: Study of the Quaternization of Poly(4-vinylpyridine). Macromolecules 1998, 31, 7111-7114, https://doi.org/10.1021/ma9805021.

3. Dautzenberg, H.; Jaeger, W.; Kiitz, J.; Philipp, B.; Seidel, C.; Stscherbina, D. Polyelectrolytes, Formation, Characterization and Application. Carl Hanser Verlag, Munich, 1994; pp. xiv + 343.

4. Abdeen, Z.; Badawi, A.; Adawi, A.; Eldidamony, A.; Ahmed, A.; Hafez, E. Effect of sonication irradiation on degradation of refinery petroleumwastewater using the prepared cationic silyl polymeric surfactant. ChemXpress 2016, 9, 030-045.

5. Chauhan, G.S.; Lal, H.; Mahajan, S.; Bansal, M. Synthesis and characterization of 4-vinyl pyridine-grafted Teflon-PFA film for water technologies. Journal of Polymer Science Part A: Polymer Chemistry 2000, 38, 4506-4518, https://doi.org/10.1002/1099-0518(20001215)38:24<4506::AID-POLA190>3.0.CO;2-U.

6. Chauhan, G.S.; Singh, B.; Dhiman, S.K. Functionalization of poly(4-vinyl pyridine) grafted cellulose by quaternization reactions and a study on the properties of postquaternized copolymers. Journal of Applied Polymer Science 2004, 91, 2454-2464, https://doi.org/10.1002/app.13406.

7. Díez-Pascual, A.M. Antimicrobial Polymer-Based Materials for Food Packaging Applications. Polymers 2020, 12, https://doi.org/10.3390 /polym12040731.

8. Shaban, S.M.; Aiad, I.; Moustafa, A.H.; Aljoboury, O.H. Some alginates polymeric cationic surfactants; surface study and their evaluation as biocide and corrosion inhibitors. Journal of Molecular Liquids 2019, 273, 164-176, https://doi.org/10.1016/j.molliq.2018.10.017.

9. Shaban, S.M.; Aiad, I.; Yassin, F.A.; Mosalam, A. The Tail Effect of Some Prepared Cationic Surfactants on Silver Nanoparticle Preparation and Their Surface, Thermodynamic Parameters, and Antimicrobial Activity. Journal of Surfactants and Detergents 2019, 22, 1445-1460, https://doi.org/10.1002/jsde.12318.

10. Aiad, I.A.; Badawi, A.M.; El-Sukkary, M.M.; El-Sawy, A.A.; Adawy, A.I. Synthesis and Biocidal Activity of Some Naphthalene-Based Cationic Surfactants. Journal of Surfactants and Detergents 2012, 15, 223-234, https://doi.org/10.1007/s11743-011-1286-z.

11. Shaban, S.M.; Elsamad, S.A.; Tawfik, S.M.; Abdel-Rahman, A.A.H.; Aiad, I. Studying surface and thermodynamic behavior of a new multi-hydroxyl Gemini cationic surfactant and investigating their performance as corrosion inhibitor and biocide. Journal of Molecular Liquids 2020, 316, https://doi.org/10.1016/j.molliq.2020.113881.

12. Ismail, D.A.; Ahmed, H.M.; Ismail, A.R.; Ahmad, S.M. Cationic Bola Form Metallosurfactants Based on Isothiouronium, Synthesis and Anti-Microbial Activity. Tenside Surfactants Detergents 2020, 57, 375-381, https://doi.org/10.3139/113.110701.

13. He, S.; Chen, H.; Tan, J.; Zhang, Y. Synthesis and surface activity of phenylselenide-1-undecyl trimthylamonium bromide. Journal of Dispersion Science and Technology 2020, 41, 1401-1409, https://doi.org/10.1080/01932691.2019.1623693.

14. Gawali, I.T.; Usmani, G.A. Synthesis, surface active properties and applications of cationic gemini surfactants from triethylenetetramine. Journal of Dispersion Science and Technology 2020, 41, 450-460, https://doi.org/10.1080/01932691.2019.1584112.

15. Zaky, M.F.; Sabbah, I.A.; Hendawy, M.E.; Abdel Hameed, R.S.; Negm, N.A. Synthesis, Characterization, and Surface Activities of Polymeric Cationic Thiol Surfactants in Aqueous Medium. Journal of Surfactants and Detergents 2019, 22, 265-274, https://doi.org/10.1002/jsde.12233.

16. Wu, J.; Gao, H.; Shi, D.; Yang, Y.; Zhang, Y.; Zhu, W. Cationic gemini surfactants containing both amide and ester groups: Synthesis, surface properties and antibacterial activity. Journal of Molecular Liquids 2020, 299, https://doi.org/10.1016/j.molliq.2019.112248.

17. Betiha, M.A.; El-Henawy, S.B.; Al-Sabagh, A.M.; Negm, N.A.; Mahmoud, T. Experimental evaluation of cationic-Schiff base surfactants based on 5-chloromethyl salicylaldehyde for improving crude oil recovery and bactericide. Journal of Molecular Liquids 2020, 316, https://doi.org/10.1016/j.molliq.2020.113862.

18. Obłąk, E.; Piecuch, A.; Rewak-Soroczyńska, J.; Paluch, E. Activity of gemini quaternary ammonium salts against microorganisms. Applied Microbiology and Biotechnology 2019, 103, 625-632, https://doi.org/10.1007/s00253-018-9523-2.

19. Marschelke, C.; Fery, A.; Synytska, A. Janus particles: from concepts to environmentally friendly materials and sustainable applications. Colloid and Polymer Science 2020, 298, 841-865, https://doi.org/10.1007/s00396-020-04601-y.

20. Günther, F.; Xie, Q.; Harting, J. Equilibrium Orientation and Adsorption of an Ellipsoidal Janus Particle at a Fluid-Fluid Interface. Colloids and Interfaces 2020, 4, https://doi.org/10.3390/colloids4040055.

21. Anzivino, C.; Chang, F.; Soligno, G.; van Roij, R.; Kegel, W.K.; Dijkstra, M. Equilibrium configurations and capillary interactions of Janus dumbbells and spherocylinders at fluid-fluid interfaces. Soft Matter 2019, 15, 2638-2647, https://doi.org/10.1039/c8sm02361a. 
22. Xie, Q.; Harting, J. Controllable Capillary Assembly of Magnetic Ellipsoidal Janus Particles into Tunable Rings, Chains and Hexagonal Lattices. Advanced Materials 2021, 33, https://doi.org/10.1002/adma.202006390.

23. Labena, A.; Hamed, A.; Ismael, E.H.I.; Shaban, S.M. Novel Gemini Cationic Surfactants: Thermodynamic, Antimicrobial Susceptibility, and Corrosion Inhibition Behavior against Acidithiobacillus ferrooxidans. Journal of Surfactants and Detergents 2020, 23, 991-1004, https://doi.org/10.1002/jsde.12437.

24. Mei, L.; Zhu, S.; Yin, W.; Chen, C.; Nie, G.; Gu, Z.; Zhao, Y. Two-dimensional nanomaterials beyond graphene for antibacterial applications: current progress and future perspectives. Theranostics 2020, 10, 757781, https://doi.org/10.7150/thno.39701.

25. Ninomiya, R.; McNamee, C.E. Interaction of different lipoprotein types with cholesterol at the air/water interface. Heliyon 2020, 6, 1-12, https://doi.org/10.1016/j.heliyon.2020.e04545.

26. El-Shamy, O.A.A.; Habib, A.O.; Mohamed, D.E.; Badawi, A.M. Synthesis, Characterization, Surface, and Thermodynamic Studies of Alkyl Tetrachloroferrates: Performance Evaluation of Their Nanostructures as Biocides. Journal of Surfactants and Detergents 2020, 23, 215-223, https://doi.org/10.1002/jsde.12349.

27. Pérez, L.; Pinazo, A.; Morán, M.C.; Pons, R. Aggregation Behavior, Antibacterial Activity and Biocompatibility of Catanionic Assemblies Based on Amino Acid-Derived Surfactants. International Journal of Molecular Sciences 2020, 21, 8912-8934, https://doi.org/10.3390/ijms21238912.

28. Pinazo, A.; Pons, R.; Marqués, A.; Farfan, M.; da Silva, A.; Perez, L. Biocompatible Catanionic Vesicles from Arginine-Based Surfactants: A New Strategy to Tune the Antimicrobial Activity and Cytotoxicity of Vesicular Systems. Pharmaceutics 2020, 12, 857-881, https://doi.org/10.3390/pharmaceutics12090857.

29. Eftekhari, M.; Schwarzenberger, K.; Javadi, A.; Eckert, K. The influence of negatively charged silica nanoparticles on the surface properties of anionic surfactants: electrostatic repulsion or the effect of ionic strength? Physical Chemistry Chemical Physics 2020, 22, 2238-2248, https://doi.org/10.1039/c9cp05475h.

30. Singh, I.; Dhawan, G.; Gupta, S.; Kumar, P. Recent Advances in a Polydopamine-Mediated Antimicrobial Adhesion System. 2021, 11, https://doi.org/10.3389/fmicb.2020.607099.

31. An, X.; Erramilli, S.; Reinhard, B.M. Plasmonic nano-antimicrobials: properties, mechanisms and applications in microbe inactivation and sensing. Nanoscale 2021, 13, 3374-3411, https://doi.org/10.1039/D0NR08353D.

32. Mohamed, H.I.; Basyouni, M.Z.; Khalil, A.A.; Hebash, K.A.; Tantawy, A.H. Petroleum-dispersing and antimicrobial activity of newly synthesized polymeric surfactants tethering tetrachlorophthalimide moiety. Journal of the Iranian Chemical Society 2021, 18, 265-274, https://doi.org/10.1007/s13738-020-02023-9.

33. Kumar, S.; Lee, S.; Thomas, R.G.; Lee, S.-J.; Lee, H.-J.; Park, I.-K.; Jeong, Y.Y.; Yoon, T.-H.; Shin, D.-C.; Lee, J.-S. Self-emulsion polymerization of amphiphilic monomers - a green route to synthesis of polymeric nanoscaffolds. Journal of Polymer Science Part A: Polymer Chemistry 2019, 57, 1165-1172, https://doi.org/10.1002/pola.29370.

34. Adawy, A.I.; Abdeen, Z.I.; Abdel Rahman, N.R.; Ali, H.E.S. Evaluation of the biological activity of the prepared nonionic polymeric based on the acrylated polyethylene glycol. Journal of Molecular Liquids 2019, 288, https://doi.org/10.1016/j.molliq.2019.111010.

35. Cheng, Q.; Asha, A.B.; Liu, Y.; Peng, Y.-Y.; Diaz-Dussan, D.; Shi, Z.; Cui, Z.; Narain, R. Antifouling and Antibacterial Polymer-Coated Surfaces Based on the Combined Effect of Zwitterions and the Natural Borneol. ACS Applied Materials \& Interfaces 2021, 13, 9006-9014, https://doi.org/10.1021/acsami.0c22658.

36. Lei, Q.; Lai, X.; Zhang, Y.; Li, Z.; Li, R.; Zhang, W.; Ao, N.; Zhang, H. PEGylated Bis-Quaternary TriphenylPhosphonium Tosylate Allows for Balanced Antibacterial Activity and Cytotoxicity. ACS Applied Bio Materials 2020, 3, 6400-6407, https://doi.org/10.1021/acsabm.0c00837.

37. Panigrahi, A.; Are, V.N.; Jain, S.; Nayak, D.; Giri, S.; Sarma, T.K. Cationic Organic Nanoaggregates as AIE Luminogens for Wash-Free Imaging of Bacteria and Broad-Spectrum Antimicrobial Application. ACS Applied Materials \& Interfaces 2020, 12, 5389-5402, https://doi.org/10.1021/acsami.9b15629.

38. Izzo, L.; Matrella, S.; Mella, M.; Benvenuto, G.; Vigliotta, G. Escherichia coli as a Model for the Description of the Antimicrobial Mechanism of a Cationic Polymer Surface: Cellular Target and Bacterial Contrast Response. ACS Applied Materials \& Interfaces 2019, 11, 15332-15343, https://doi.org/10.1021/acsami.9b02903. 